\title{
CRANIOFACIAL LINE OF TELERADIOGRAPHY AND ITS MEANING AT CEPHALOMETRY
}

Article history:

Submitted 19March 2019

Accepted 10 July 2019
Vladimir Shkarin', Vasily Grinin', Ruslan Halfin', Tatyana Dmitrienko ${ }^{4}$, Dmitry Domenyuk $k^{5 *}$, Igor Fomin ${ }^{6}$

\author{
${ }^{1}$ Department of Public Health and Postgraduate Education, Volgograd \\ state medical university, Volgograd, Russia \\ ${ }^{2}$ I.M. Sechenov First Moscow State Medical University, Moscow, Russia \\ ${ }^{3}$ Graduate School of Health Management, I.M. Sechenov First Moscow \\ State Medical University, Moscow, Russia \\ ${ }^{4}$ Department of Dentistry, Pyatigorsk Medical-Pharmaceutical Institute \\ (Branch of Volgograd State Medical University, Pyatigorsk, Russia \\ ${ }^{5}$ Department of general practice dentistry and child dentistry, Stavropol \\ State Medical University, Stavropol, Russia \\ ${ }^{6}$ Department of Orthopedic and General Dentistry, I.M. Sechenov First \\ Moscow State Medical University, Moscow, Russia
}

*Corresponding Author: domenyukda@mail.ru

\section{INTRODUCTION}

Cephalometric analysis is an integral part of diagnostics in orthodontics and prosthetic dentistry [8]. A special emphasis is placed on the spatial location of the jaws regarding the major anatomical craniofacial points. This principle lays the basis for classifications of anomalies of the maxillofacial area and the differential diagnostics of gnathic, dentoalveolar, and articular pathologies $[3,10]$. Cephalometric analysis of head teleradiography in the lateral projection is performed both manually and by machine (computer). The analysis is based on measurements between common coordinate points. The said points serve a guideline for constructing horizontal planes (lines), each of them being of a diagnostic value and serves as a guideline for carrying out angular measurements [7]. The horizontal lines divide the craniofacial area into sections. The spinal plane, for instance, separates the face gnathic part, while the occlusal plane separates the jaws between themselves. These studies are of both applied and clinical value. There has been a relationship detected between the size of the craniofacial complex and the dental arches parameters, both in physiological and pathological occlusion $[1,4,5,6]$. Such studies often determine orthodontic and prosthetic treatment tactics $[2,9,11,12]$. However, we saw no marks that would allow delineating the border between the facial part of the skull and the cranial one. Since there is no reference point then there is no data regarding the relation between the craniofacial plane and the other teleradiography reference points, which determined the objectives of this study.

Aim of study

To identify anatomical marks for constructing the craniofacial plane and to evaluate its relationship with the teleradiography major planes.

\section{MATERIAL AND METHODS}

While analyzing lateral telegraphs, we employed anatomical reference points that are commonly accepted in clinical and anthropometric studies.

To build the craniofacial line, we used the nasal point $(\mathrm{N})$ located at the junction of the frontal and nasal bones. Another mark was the point of condylion (Cond), sprawling on the upper point of the articular head of the mandible condylar process. The line ran diagonally and separated the facial and cranial parts of the skull. Given that, we proposed to mark this line as a craniofacial one. We identified the interrelation between the craniofacial line and the mandibular plane. The resulting angle was marked as maxillofacial. In addition, the location of the angle in relation to the skull structures was identified. The results were evaluated in groups of people with different types of the facial area growth, namely with a neutral, a horizontal and a vertical type. The statistical processing was performed following common requirements.

\section{RESULTS AND ITS DISCUSSION}

People with a neutral growth trend in the facial part had the mandibular angle varying within the range of $119^{\circ}$ to $124^{\circ}$. A decrease in the angle resulted in the horizontal type of growth, whereas an increase - in the vertical one. The mandibular angle correlated with the size of the maxillofacial angle, which, in case of a neutral type of growth, ranged from $40^{\circ}$ to $45^{\circ}$. Notable is the spatial arrangement of the angle. In case of the vertical growth, the angle shaped by the intersection of the craniofacial and mandibular lines was located on the skull occipital bone and descended in case of the neutral and, even more, the horizontal growth type.

\section{CONCLUSION}

The above means that the craniofacial plane of the lateral telegraphy can be used to construct the 
maxillofacial angle, which, in turn, may be used as a criterion for identifying the facial area growth type. The proposed method can be used in clinical orthodontics to diagnose various anomalies, as well as to determine the tactics for comprehensive treatment, and to check its efficiency.

\section{REFERENCES}

1. Borodina V.A., Domenyuk D.A., Veisgeim L.D., DMitrienko S.V. Biometry of permanent occlusion dental arches - comparison algorithm for real and design indicators. Archiv EuroMedica, 2018; Vol. 8; 1: 25-26. https://doi.org/10.35630/2199. $885 \mathrm{X} / 2018 / 8 / 1 / 25$

2. DMitrienko S.V., Domenyuk D.A., KoChKonyan A.S., Karslieva A.G., DMitrienKo D.S. Interrelation between sagittal and transversal sizes of maxillary dental arches. Archiv EuroMedica, 2014; Vol. 4; 2: 10-13.

3. DMitrienko S.V., DaVydov B.N., V.V. ShKarin, DoMENYUK D.A. Algorithm for determining the size of artificial teeth by the morphometric parameters of the face in people with full adentia. Dentistry. 2018; 97(6): 57-60. DOI - 10.17116/stomat20189706157

4. ShKarin V.V., Davydov B.N., Domenyuk D.A., DMitrienko S.V. Non-removable arch orthodontic appliances for treating children with congenital maxillofacial pathologies - efficiency evaluation. Archiv EuroMedica, 2018; Vol. 8; 1: 97-98. https://doi. org/10.35630/2199-885X/2018/8/1/97

5. DomenYuk D.A., ShKarin V.V., Porfiriadis M.P., Dmitrienko D.S., Dmitrienko S.V. Algorithm for forecasting the shape and size of dent arches front part in case of their deformations and anomalies. Archiv EuroMedica, 2017; Vol. 7; 2: 105-110.

6. Domenyuk D.A., Vedeshina E G., Dmitrienko S.V. Mistakes in Pont (Linder-Hart) method used for diagnosing abnormal dental arches in transversal plane. Archiv EuroMedica, 2016; Vol. 6; 2: 23-26.

7. Domenyuk D.A., Lepilin A.V., Fomin I.V., DMitrienKo S.V., BUDAYCHIEV G.M-A. Improving odontometric diagnostics at jaw stone model examination. Archiv EuroMedica, 2018; Vol. 8; 1: 34-35. https://doi.org/10.35630/2199-885X/2018/8/1/34

8. Korobkeev A.A., Domenyuk D.A., SHKarin V.V., Dmitrienko S.V. Types of facial heart depth in physiological occlusion. Medical news of North Caucasus. 2018. - Vol. 13. - № 4. - P. 627-630. (In Russ., English abstract). DOI - https://doi.org/10.14300/ mnnc.2018.13122

9. Lepilin A.V., Fomin I.V., Domenyuk D.A., Dmitrienko S.V. Diagnostic value of cephalometric parameters at graphic reproduction of tooth dental arches in primary teeth occlusion. Archiv EuroMedica, 2018; Vol. 8; 1: 37-38. https://doi. org/10.35630/2199-885X/2018/8/1/37

10. Shkarin V.V., Porfiriadis M.P., Domenyuk D.A., DMitrienko D.S., DMitriEnKo S.V. Setting refer- ence points for key teeth location in case of abnormal dental arch shape. Archiv EuroMedica, 2017; Vol. 7; 2: 111-117.

11. Korobkeev A. A., Domenyuk D. A., ShKarin V. V., DMitrienko S. V., Mazharov V. N. Variability of odontometric indices in the aspect of sexual dimorphism. Medical News of North Caucasus. 2019;14(1.1):103-107. DOI - https://doi. org/10.14300/mnnc.2019.14062 (In Russ.)

12. Dmitrienko T.D., Domenyuk D.A., Porfyriadis M.P., Arutyunova A.G., Kondratyuk A.A., Subbotin R.S. Connection between clinical and radiological torque of medial incisors at physiological occlusion. Archiv EuroMedica, 2019; Vol. 9; 1: 29-37. https://doi.org/10.35630/2199-885X/2019/9/1/29 